\title{
Assessing The Feasibility and Acceptability of A Cluster-Randomized Study of Cognitive Behavioral Therapy For Chronic Insomnia In A Primary Care Setting
}

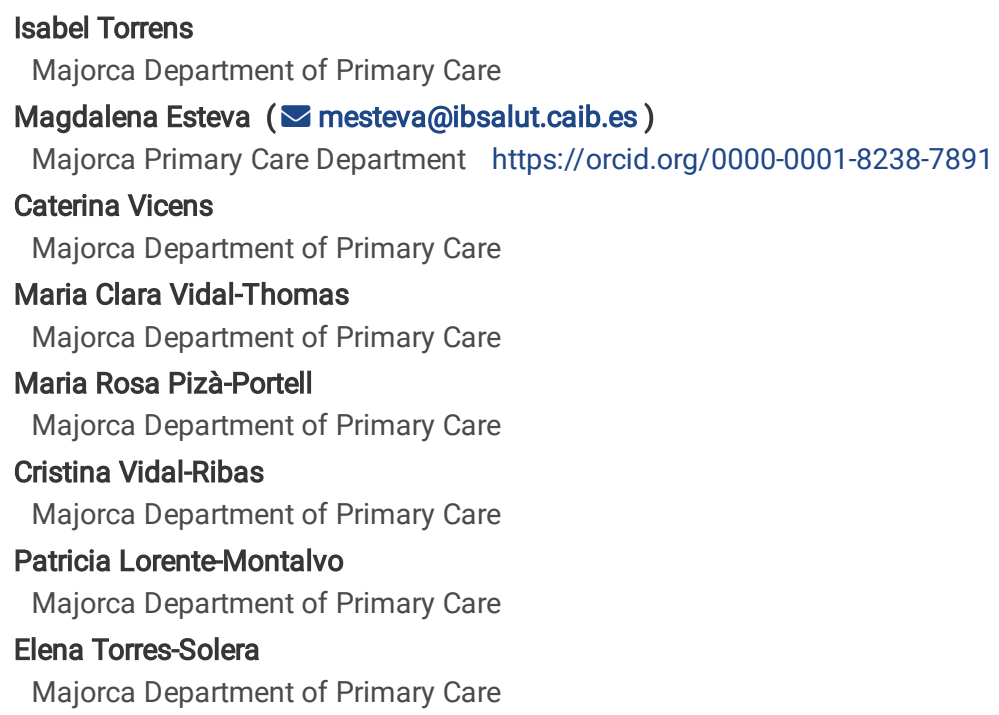

Version of Record: A version of this preprint was published at BMC Family Practice on April 16th, 2021. See the published version at https://doi.org/10.1186/s12875-021-01429-5. 


\section{Abstract}

Background: Cognitive behavioral therapy (CBT) is the treatment of choice for chronic insomnia but is underutilized in patients in primary care. The purpose of this study was to assess the feasibility and acceptability of a pilot cluster-randomized study of CBT for chronic insomnia (CBT-i) in a primary care setting.

Methods: This pilot-feasibility study with a parallel cluster-randomized design comparing CBT-i-intervention group (IG) and usual care (UC) was performed at two primary health care centers in Majorca, Spain. Patients were included if they were 18 to 65 years-old; had diagnoses of chronic insomnia according to the Insomnia Severity Index (ISI $\left.{ }^{3} 8\right)$ and had insomnia longer than 3 months; and did or did not use a hypnotic medication. A total of 25 GPs and nurses and 32 patients were randomly allocated to two groups. The outcome of the intervention was improvement in quality of sleep. Other primary outcomes were the feasibility and applicability of the intervention, which were defined using nominal groups. UC was defined based on previous studies. The recruitment process, compliance with intervention sessions, and patient retention were also assessed.

Results: We adapted the CBT-i approach of Morin to a primary care context. After intervention training, primary care providers (PCPs) expressed the need for more extensive training in the different aspects of the therapy and the discussion of more cases. PCPs considered the intervention as adequate but wanted fewer and shorter sessions as well as to discard the cognitive restructuring component. PCPs considered it crucial to prepare each session in advance and to establish a specific agenda for the CBT-i. Regular reminders given to PCPs and patients were suggested to improve study participation. Compared to the UC group, significantly higher proportions of patients in the IG had short sleep latency, slept for longer than $5 \mathrm{~h}$, and had fewer sleep disruptions.

Conclusions: This pilot-feasibility study identified several key issues that must be addressed before performing CBT-i intervention in future clinical trials in a primary care setting.

Trial registration: NCT04565223. (Clinical trials.gov) Registered 1 September 2020 - Retrospectively registered.

\section{Background}

Insomnia is a disorder characterized by difficulties in falling asleep and staying asleep during the night or the perception of having a non-restful sleep [1]. It is the most common sleep disorder in the general population, and affects $6.4 \%$ of population in Spain, and this percentage increases to $20.8 \%$ if it includes individuals with some related symptoms that occur 2 or 3 times per week [2,3]. Chronic insomnia is a significant burden to society because it can lead to the development of physical $[4,5]$ and psychological disorders, increase the risk of road accidents [6, 7], and lead to excessive sick leave [5] and greater use of health care services $[8,9]$.

In spite of its high prevalence and association with multiple health problems, there is only limited availability of effective treatments for insomnia. Hypnotic medications often effectively alleviate symptoms, but can lead to side-effects, dependency, and tolerance [10, 11]. Cognitive behavioral therapy for insomnia (CBT-i) is a multicomponent intervention which focuses on cognitive and behavioral factors that contribute to sleep disorders [12]. The results of recent systematic reviews showed that CBT-i provided by psychologists and psychiatrics is more effective than usual treatments [13] and medications, and it also lasts longer [14], even in patients with comorbidities [15].

However, the efficacy of CBT-i when applied by general practitioners (GPs) or primary care (PC) nurses has not been demonstrated. A study that compared CBT-i provided by PC nurses with usual care provided by a GP indicated that CBT-i was associated with improvements in self-reported sleep latency, wakefulness after sleep onset, and sleep efficiency, and that patients receiving usual care did not improve [16]. Another study of CBT-i provided by PC nurses [17] also showed that this intervention provided distinct reductions in night awakening and sleep latency.

CBT-i is underused by GPs and PC nurses for several reasons. This therapy is not designed for use by primary care providers (PCPs) [18], it requires significant effort to motivate patients to change their behaviors [19], and it can be very time-consuming. In addition, PCPs typically lack the skills to administer CBT-i and many do not consider insomnia an important issue [20,21]. However, most patients with insomnia are diagnosed in primary care settings [22]. Thus it is necessary to have an effective CBT-i that is adapted to the skills of PCPs, because implemented of therapy in this setting may have a greater impact.

Before designing a large trial to test the effectiveness of a CBT-i intervention in PC patients with insomnia, we performed the current mixture of a pilot study and a feasibility study. This current study examined many of the procedures to be used in a future trial in an effort to prevent problems during this upcoming trial [23].

\section{Objectives}

The primary objectives of this pilot-feasibility study were:

1. To design and adapt a brief CBT-i intervention to be provided by PCPs for the treatment of chronic insomnia in individuals who are 18 to 65 yearsold.

2. To define usual care (UC) for the treatment of chronic insomnia provided by PCPs as a comparative intervention (control group). 
3. To assess the training activities for the CBT-i intervention by determining GPs' and nurses' satisfaction with the content and applicability of the intervention.

4. To determine the acceptability of the intervention by GPs and nurses.

5. To assess PCPs and patient recruitment, follow-up, and adherence to the intervention

The secondary objective was to assess the quality of sleep in patients after 3 months of the CBT-i.

\section{Methods Design}

This is a pilot-feasibility two-arm cluster-randomized trial comparing CBT-i and usual care (UC). The allocated groups were primary care doctors, nurses and psychologists (the clusters). The study was performed from September 2014 to April 2015 at two primary health care centers of Majorca (Spain) with 56,000 registered inhabitants. This study adheres to CONSORT guidelines.

\section{Subject recruitment}

Sixteen GPs, 7 nurses, and 2 psychologists who expressed interest in the study were recruited in September 2014. They were each given a list of 6 patients with chronic insomnia, and each of them selected 2 patients from the list who were eligible. Patients with chronic insomnia who visited their GPs or family nurses could also be recruited. Patients were included if they were 18 to 65 years-old; had diagnoses of chronic insomnia according to the Insomnia Severity Index (ISI $\geq 8)[30,31]$ and had insomnia longer than 3 months; and did or did not use a hypnotic medication. Patients were excluded if any of the following conditions were present: secondary insomnia or another sleep disorder, such as restless legs syndrome, parasomnia, or alterations of the circadian rhythm (e.g., due to shift work), or use of a medication that could produce sleep alterations; severe psychiatric disorder; depression (HADS score $\geq 8$ ) or diagnosis of major depression in the clinical records; suicide attempt; use of an antidepressant or anti-psychotic medication; alcohol or drug abuse during the last year; receipt of another CBT-i; chronic disease, such as sleep apnea; diagnosis of dementia or presence of a cognitive deficit (Mini Mental State Evaluation (MME) score < 23); neurodegenerative or oncological disease with poor prognosis; mental or physical incapacities that impeded participation in interviews [32-33]; acute or chronic pain secondary to a rheumatic disease or another untreated chronic disease; pregnancy; or participation in a previous clinical trial in the participating health centers.

Patients were invited to participate personally or by telephone. If a patient agreed, an appointment in the health care center was scheduled, at which they received oral and written information about the study. If a patient was accepted and deemed eligible, he or she completed the ISI questionnaire to confirm the presence of chronic insomnia, signed an informed consent agreement, and received an appointment for a baseline evaluation.

\section{Group allocations and blinding}

GPS and nurses were randomized (1:1) to the CBT-i intervention group (IG) or the usual care group (UCG) using computer generated random numbers by the Research Unit study manager. PCPs were allocated in the IG once they had selected at least two patients of their list. The two psychologists (ET and MRPP), CV, and IT were allocated to the intervention group because these individuals have the expertise to provide thorough and accurate information about the implementation of the intervention and the need for further training. Blinding of patients and clinicians was not possible due to the nature of the intervention; the assistant researcher was also not blinded, because this person conducted interviews at 3 months that included treatment-specific questions. The objectives of this pilot-feasibility study focus on assessment of clinical trial processes, not on patients' outcomes.

\section{Collection of information and follow up}

Intervention

The CBT-i intervention was developed by two family physicians (IT and CV) and two psychologists (ET and MRP-P). First, a review of the literature on the use of CBT-i was performed, with a focus on interventions applied in primary care. After a literature review, the CBT-i approach designed by Morin [12] was adapted to our setting, in which there were fewer sessions and shorter sessions. The CBT-i included sleep hygiene counseling, stimulus control, cognitive restructuring, relaxation techniques, and benzodiazepine therapy or withdrawal (when needed). To conduct the intervention, guidelines for GPs and nurses and graphic and written materials for patients (sleep diary, registry of behavior habits, and cognitive problems) were developed.

Usual care

The usual treatment for persistent insomnia in a primary care setting was previously described in two cross-sectional studies performed by general practitioners and family nurses of the Primary Care Majorca Department during 2011 and 2015 [24, 25].

\section{Measurements}

The primary measures were: design of the CBT-i intervention; assessment of the acceptability of the training of PCPs (satisfaction with the content, applicability, and ability to provide sufficient training); feasibility of the designed intervention for administration by trained GPs and nurses; and feasibility of the study design (recruitment, follow up, and retention). 
The measures used to assess the potential effectiveness of the intervention were measured at baseline interview and at 3 months post-treatment; they included the Pittsburgh Sleep Quality Index (PSQI) [26-27]; the Hospital Anxiety and Depression Scale (HADS)[29, 30] and use of hypnotic medications. The PSQI is a 19-item self-reported questionnaire that assesses 7 clinical relevant components of sleep quality (subjective sleep quality, sleep latency, sleep duration, sleep efficiency, sleep disturbances, use of sleep medication and daytime dysfunction) in the preceding month. Each component is rated on 0 to 3 point scale referring to the composite score derived from the frequencies of each disturbance, in which 0 is equal to not in the past month and 3 is equal to 3 or more times a week, with a global score (the sum of the 7 component scores) ranging from 0 to 21 . A cut off score of 5 has been shown to discriminate between good and bad sleepers [26-27].

The HADS measures anxiety and depression levels. It is a 14-item self-report scale with a 7-item anxiety subscale and a 7-item depression subscale. Each item is scored on a 4-point Likert scale (e.g., as much as I always do 0; not quite so much 1; definitely not so much 2; and not at all 3), giving maximum subscale scores of 21 for each of depression and anxiety. The questionnaire assesses symptoms over the preceding week. Patients with scores $>10$ are considered to have morbidity. Scores between 8 and 10 were considered as borderline cases and scores $<8$ were considered to indicate the absence of relevant morbidity $[28,29]$. Use of hypnotic medications was also recorded, as reported by patients and verified from clinical records.

In addition, adverse effects at 3 months after the intervention that could be associated with the CBT-i or benzodiazepine discontinuation (tremor, irritability, anxiety, insomnia, and seizure) were recorded, and their severities were rated as none, mild, moderate, or severe. Therapists were asked to report any serious adverse events during the follow-up period to the research coordinator.

The independent variables were group allocation; socio demographic characteristics (sex, age, level of education, and marital status); and comorbidities.

This study received approval from the Majorca Primary Care Research Committee (No PI14-19).

\section{CBT-i training}

All doctors and nurses were trained on data collection procedures and administration of questionnaires and psychometric scales. Then, those who were allocated to the intervention group received training in CBT-i from the two psychologists (ET and IT). This training ( 2 sessions, $2 \mathrm{~h}$ per session) explained the content of the planned intervention and presented a case report. After the training sessions, a group session was conducted in which one investigator (ME), using a script containing questions on the different dimensions, collected the opinions of the doctors and nurses regarding the adequacy, content, and duration of their training, and to ask for their ideas about possible improvements.

\section{Acceptability of the intervention by GPs and nurses}

To assess acceptance of the intervention by PCPs, two nominal groups were established, one in each health center. These nominal groups consisted of one member of the research group and one observer. The group discussions were designed to follow the nominal group process [34] regarding the introduction and clarification of the research task; individual generation of ideas; generation of ideas as a group (proposing ideas for recording on a flip chart); refining the list of ideas by adding, merging, or removing certain ideas; individually ranking the five most important ideas; and then a group review of the aggregate ranking of ideas. The introduction included obtaining consent from all participants. The observer tasks included assuring that all topics in the script were considered during nominal group development.

\section{Patient recruitment, follow-up, and adherence to the intervention}

To assess the patient recruitment process, study acceptance, and adherence to the intervention, the numbers of patients who were initially contacted, who agreed to participate, who were lost to follow-up, and who received a final evaluation were recorded.

Statistical analysis for the secondary objective: To assess the effect of CBT-i in the measurement of quality of sleep, we used the chi square test with a level of confidence of $95 \%$. As the sample size was very small, we used the likelihood ratio test for contingency tables in those comparisons where the expected frequencies were less than 5 .

\section{Results}

Description of the intervention

We developed the CBT-i program for implementation by PC family doctors, nurses, and even primary care psychologists. The intervention requires active participation of patients for the treatment of insomnia. There were 5 individual sessions of approximately 20 min each, with one session per week or every two weeks (based on patient preference) and an additional session for patients undergoing withdrawal of hypnotic medications [35]. Table 1 describes the content of each session. 
Table 1

Summary of the intervention sessions.

\begin{tabular}{|c|c|c|c|c|c|c|c|c|}
\hline & TO & Session 1 & Session 2 & Session 3 & Session 4 & $\begin{array}{l}\text { Session } 5 \\
\text { (hypnotic } \\
\text { withdrawal) }\end{array}$ & Session $5 / 6$ & T3 \\
\hline Objectives & $\begin{array}{l}\text { 1. Baseline } \\
\text { evaluation } \\
\text { 2. Provide } \\
\text { information } \\
\text { on the } \\
\text { intervention }\end{array}$ & $\begin{array}{l}\text { 1.Identify the } \\
\text { factors that } \\
\text { perpetuate } \\
\text { insomnia } \\
\text { (behavior- } \\
\text { problem) } \\
\text { 2. Identify } \\
\text { beliefs and } \\
\text { predispositions } \\
\text { to change } \\
\text { 3. Establish } \\
\text { objectives } \\
\text { (behavior-goal) }\end{array}$ & $\begin{array}{l}\text { 1. Review } \\
\text { difficulties } \\
\text { and } \\
\text { changes } \\
\text { during the } \\
\text { week } \\
\text { 2. Identify } \\
\text { factors in } \\
\text { the patient's } \\
\text { environment } \\
\text { related with } \\
\text { going to } \\
\text { sleep } \\
\text { 3.Establish } \\
\text { objectives } \\
\text { of sleep } \\
\text { hygiene } \\
\text { modification }\end{array}$ & $\begin{array}{l}\text { 1. Review } \\
\text { difficulties } \\
\text { and } \\
\text { changes } \\
\text { during the } \\
\text { week } \\
\text { 2. Identify } \\
\text { the times a } \\
\text { patient } \\
\text { gives to } \\
\text { certain } \\
\text { habits and } \\
\text { develop a } \\
\text { timetable } \\
\text { 3. Establish } \\
\text { objectives } \\
\text { of sleep } \\
\text { hygiene } \\
\text { modification }\end{array}$ & $\begin{array}{l}\text { 1. Review } \\
\text { difficulties } \\
\text { and } \\
\text { changes } \\
\text { during the } \\
\text { week } \\
\text { 2. Identify } \\
\text { distorting } \\
\text { beliefs } \\
\text { 3. } \\
\text { Transform } \\
\text { and } \\
\text { implement } \\
\text { realistic } \\
\text { thinking }\end{array}$ & $\begin{array}{l}\text { 1. Review } \\
\text { problems related } \\
\text { to } \\
\text { benzodiazepine } \\
\text { consumption } \\
\text { 2. Negotiate with } \\
\text { the patient to } \\
\text { implement a } \\
\text { gradual dose } \\
\text { reduction }\end{array}$ & $\begin{array}{l}\text { 1. Review the } \\
\text { Sleep Diary } \\
\text { 2. Assess the } \\
\text { sessions and } \\
\text { identify what } \\
\text { has been } \\
\text { accomplished } \\
\text { 3.Assess } \\
\text { what was not } \\
\text { accomplished } \\
\text { and the next } \\
\text { goals }\end{array}$ & $\begin{array}{l}\text { 1.Follow up } \\
\text { assessment } \\
\text { at } 3 \text { months } \\
\text { after the } \\
\text { end of CBT-i }\end{array}$ \\
\hline Techniques & & $\begin{array}{l}\text { Structured } \\
\text { interview } \\
\text { Relaxation }\end{array}$ & $\begin{array}{l}\text { Sleep } \\
\text { hygiene } \\
\text { Stimulus } \\
\text { Control } \\
\text { Relaxation }\end{array}$ & $\begin{array}{l}\text { Restriction } \\
\text { of bed time } \\
\text { Paradoxical } \\
\text { intention } \\
\text { Relaxation }\end{array}$ & $\begin{array}{l}\text { Cognitive } \\
\text { restructuring } \\
\text { Relaxation }\end{array}$ & $\begin{array}{l}\text { Structured } \\
\text { interview }\end{array}$ & $\begin{array}{l}\text { Structured } \\
\text { interview }\end{array}$ & \\
\hline $\begin{array}{l}\text { Spreadsheet } \\
\text { of tasks }\end{array}$ & & Sleep diary & $\begin{array}{l}\text { How are my } \\
\text { routines? }\end{array}$ & $\begin{array}{l}\text { How are my } \\
\text { times? }\end{array}$ & $\begin{array}{l}\text { How they } \\
\text { interfere my } \\
\text { thinking's }\end{array}$ & $\begin{array}{l}\text { To release of } \\
\text { written } \\
\text { information on } \\
\text { gradual } \\
\text { reduction of } \\
\text { benzodiazepines }\end{array}$ & Sleep diary & \\
\hline $\begin{array}{l}\text { Duration } \\
\text { (min) }\end{array}$ & $20-30$ & 20 & 20 & 20 & 20 & 20 & 20 & 20 \\
\hline
\end{tabular}

This intervention aims to change the habits of the affected patients, and to encourage them to undergo a cognitive and physical deactivation before going to sleep. It aims to help patients to identify and assess how they react before, during, and after sleep and to consider thoughts and behaviors that contribute to insomnia (Behavior-Problem) with the help of a sleep diary. The intervention offers patients a wide range of structured strategies, based on their possible impact (Behavior-Goal). The patient and therapist agreed on the therapeutic objectives before commencement of treatment. These objectives determine the content of the intervention sessions. After each session, patients have a task to work on at home, in which they try to achieve different goals and use different techniques. During treatment, the therapist was available to address doubts and difficulties that the patients may experience. During the sessions, therapists were suggested to record relevant information and to administer the questionnaire.

The sleep diary contains a 2-week registry that records the following data: sleeping hours, sleep latency, duration of awakening and number of awakenings, number of times getting out of bed, naps, medication use, and sleep quality. Patients also identified the main difficulties experience during the night and reported desired objectives and how they can be achieved.

Description of usual care

The professionals in the control group followed their usual care in treatment of insomnia patients. A previous descriptive study of insomnia treatments used by GPs in Majorca from 2001 to 2012 indicated that more than 95\% of them asked patients about habits related to sleep hygiene that might lead to insomnia, $85.1 \%$ provided to advice on sleep hygiene measures, $15.1 \%$ suggested the use of herbal remedies, and $14.2 \%$ suggested CBT-i. More than $33 \%$ of GPs prescribed a pharmacological treatment. Benzodiazepines were the most prescribed drugs (33.4\%) followed by the Z drugs ( $25.7 \%$ ). Six of 10 GPs requested a review of the treatment after 1 month of medication use [24].

The usual care provided by nurses was based on a 2014 descriptive study (performed simultaneously with the present study). This study reported that $69.6 \%$ of nurses asked patients about their sleeping habits and $48.5 \%$ asked about the consequences of their insomnia. A total of $46.4 \%$ considered pharmacological interactions and $45.6 \%$ gave special consideration to elderly patients. The non-pharmacological treatments they recommended were sleep hygiene measures (76\%), herbal remedies (44.9\%), and CBT-i (22.4\%). About $25 \%$ of nurses offered written advice and $81 \%$ gave oral advice on sleep hygiene [25]. 
PCPs assessed the intervention training during a group session. This group consisted of 12 doctors ( 6 in the IG and 6 in the UCG), 3 nurses ( 2 in the IG and 1 in the UCG), and 2 psychologists.

This group's assessment of the training had several general conclusions:

- The training sessions should be longer, more practical advice should be given, and there should be more discussion of different cases.

- There is a need to provide a theoretical context for CBT-i.

- The different components of the therapy (sleep diary, identification of sleep problems, stimulus control, and relaxation) need more complete coverage.

- There is a need for more training on how to teach patients to restructure their thoughts and develop the ability to achieve concrete goals.

- The case reports described during the training sessions generated extensive input, and was considered important in clarification of some key concepts.

Acceptability and assessment of the intervention

Regarding the recruitment of patients, both groups highlighted the difficulty in identification of eligible patients with chronic insomnia, and that most patients with insomnia symptoms had other mental disorders. GPs and nurses suggested use of no age limit, increasing the ISI cut-off to 14, and consideration of clinical assessments (i.e., poor quality of life). Also, participants in the nominal groups suggested that apart from personal invitations by PCPs, invitation posters should be installed throughout the health center and in the community. All professionals agreed that time constraints were a problem for some patients. Table 2 summarizes the positive and negative aspects of the intervention in the nominal groups.

Table 2

Positive aspects and difficulties of the intervention that were reported in both nominal groups or only in one nominal group.

\section{POSITIVE ASPECTS}

Both groups

- PCPs provided valuable non-pharmacological treatment.

- There were opportunities to go deeper into the causes of insomnia.

- Other sociological and sleep hygiene problems were identified.

- The patient-therapist relationship improved.

\section{DIFFICULTIES}

- Doctors considered the goals of the intervention as too ambitious.

- It required PCPs to change their roles, in that it they had to address emotional issues.

- The intervention did not permit deep examination of other problems that emerged during the sessions.

- There were too many sessions, and some patients withdrew for this reason.

- The sessions were too short.

- Some concepts were repeated in the different sessions.

- A reorganization of agendas is needed to continue the intervention.

- The tutorial material for PCPs was considered essential to structure the therapy, but was too dense. More simplified materials are needed.

- Written material for the patient about sleep hygiene, and control of stimuli and thoughts is needed.

One group only

- There was positive support for treatment of insomnia.

- The relaxation sessions had high value.

- The "Manual of Interventions" was very helpful.

Assessment of the recruitment process and study acceptance

Figure 1 summarizes our assessment of the recruitment process and study acceptance by PCPs and patients. After study presentation in the two health centers, 25 PCPs agreed to participate (15 in the IG and 10 in the UCG). Four PCPs in each group did not recruit any eligible patients. Thus, 32 patients were recruited, 19 in the IG and 13 in the UCG. Two patients were lost to follow-up in the IG and 2 were lost to follow-up in the UCG.

Assessing the adherence to intervention

Five of the 19 patients in the IG did not complete all the scheduled sessions ( 1 attended no sessions, 1 attended one session, 2 attended two sessions, and 1 attended 3 sessions). The other 14 attended the entire schedule of 5 sessions, with a benzodiazepine withdrawal session if needed. 
Table 3 shows the socio demographic characteristics of the two groups of patients. The most notable differences were that the IG had fewer married patients and fewer patients with university level education.

Table 3

Baseline sociodemographic characteristics and ISI scores in the intervention group $(n=19)$ and control group $(n=13)$.

$\left.\begin{array}{|lll|}\hline \text { Variable } & \text { Intervention group } & \text { Control Group } \\ & \mathbf{N}(\%) & \mathbf{N}(\%)\end{array}\right)$

Table 4 shows the effects of the intervention in the two groups. Significantly higher proportions of patients in the IG had short sleep latency; slept for longer than 5 hours. 
Table 4

PSQI results, HADS results, and use of hypnotics and anti-depressants after 3 months in the intervention group $(n=19)$ and the control group $(n=13)$

\begin{tabular}{|c|c|c|c|}
\hline Variable & $\begin{array}{l}\text { Intervention group } \\
\mathrm{n}(\%)\end{array}$ & $\begin{array}{l}\text { Control Group } \\
\text { n (\%) }\end{array}$ & $P$ value \\
\hline Subjective sleep quality & $10(62.5)$ & $3(30.0)$ & 0.107 \\
\hline Very good/quite good & $6(37.5)$ & $7(70.0)$ & \\
\hline \multicolumn{4}{|l|}{ Very bad/quite bad } \\
\hline Sleep latency (min) & $14(82.4)$ & $5(45.5)$ & 0.041 \\
\hline $0-4$ & $3(17.6)$ & $6(54.5)$ & \\
\hline \multicolumn{4}{|l|}{$5-6$} \\
\hline Sleep duration (h) & $11(68.8)$ & $1(11.1)$ & 0.006 \\
\hline $5 \mathrm{~h}$ or more & $5(31.3)$ & $8(88.9)$ & \\
\hline \multicolumn{4}{|l|}{$<5 \mathrm{~h}$} \\
\hline Sleep disruptions & $15(88.2)$ & $6(54.5)$ & 0.044 \\
\hline $1-9$ & $2(11.8)$ & $5(45.5)$ & \\
\hline \multicolumn{4}{|l|}{$10-27$} \\
\hline Use of a hypnotic* & $10(58.8)$ & $4(36.4)$ & 0.408 \\
\hline None in the last month & $2(11.8)$ & $1(9.1)$ & \\
\hline 1 or 2 times per week & $5(29.4)$ & $6(54.5)$ & \\
\hline \multicolumn{4}{|l|}{3 or more times per week } \\
\hline Day dysfunction & $5(29.4)$ & $4(36.4)$ & 0.249 \\
\hline 0 & $8(47.1)$ & $2(18.2)$ & \\
\hline $1-2$ & $4(23.5)$ & $5(45.5)$ & \\
\hline \multicolumn{4}{|l|}{$3-6$} \\
\hline HADS depression* & $14(82.4)$ & $9(81.8)$ & 0.971 \\
\hline None $(0-7)$ & $3(17.6)$ & $2(18.3)$ & \\
\hline \multicolumn{4}{|l|}{ Possible ( $\geq 8)$} \\
\hline HADS anxiety & $9(52.9)$ & $6(54.5)$ & 0.934 \\
\hline None $(0-7)$ & $8(47.1)$ & $5(45.5)$ & \\
\hline \multicolumn{4}{|l|}{ Possible ( $\geq 8)$} \\
\hline Hypnotic use* & $6(42.9)$ & $2(28.6)$ & 0.276 \\
\hline No & $6(42.9)$ & $5(42.9)$ & \\
\hline Yes & $2(14.3)$ & $0(0.0)$ & \\
\hline \multicolumn{4}{|l|}{$<4$ doses/months } \\
\hline Beginning hypnotic use* & $0(0.0)$ & $1(33.3)$ & 0.117 \\
\hline Yes & $6(100.0)$ & $2(66.7)$ & \\
\hline No & & & \\
\hline
\end{tabular}




\begin{tabular}{|llll|}
\hline Variable & $\begin{array}{l}\text { Intervention group } \\
\text { n (\%) }\end{array}$ & $\begin{array}{l}\text { Control Group } \\
\mathbf{n}(\%)\end{array}$ & P value \\
\hline Beginning antidepressant use* & $1(7.1)$ & $3(33.3)$ & 0.107 \\
Yes & $13(92.9)$ & $6(66.7)$ & \\
No & & & \\
\hline *Likelihood ratio test for contingency tables & & \\
\hline
\end{tabular}

\section{Discussion}

Pilot and feasibility studies play an invaluable part in health research. The results of pilot studies allow the research team to reconsider the procedures and design of the subsequent main study. The present study provided us with important information about several fundamental issues that must be addressed before beginning a large trial to assess the effectiveness of a CBT-i intervention implemented by PC doctors and nurses in patients with persistent insomnia $[36,37,38]$.

Intervention

The present study provided 5 sessions of CBT-i and an extra session for benzodiazepine withdrawal (if necessary). We evaluated the acceptability of this intervention using the nominal group technique to obtain opinions from the PCPs. They considered the format of the intervention as adequate, but PCPs and patients advocated the use of fewer sessions and to redesign the content of the CBT-i, by removing cognitive restructuring component because PCPs do not feel comfortable with this aspect of the intervention. Also, PCPs advocated the use of an "Intervention Guide" for PCPs as a key element, and also providing written materials for patients. They suggested that the materials for patients should cover topics such as instructions for keeping a sleep diary and a guideline for sleep hygiene, stimulus control, and control of thoughts that contribute to insomnia, and that these materials should be adapted for patients with little education. The PCPs also recommended implementation of some changes in the intervention. In particular, they considered it crucial for PCPs to make certain preparations prior to each CBT-i session, establish a specific agenda, and schedule sessions at times that are less tiring for the PCP and also consider patient availability.

Training in CBT-i

We also identified the need to improve the training of PCPs by use of a longer training program and providing more presentations of cases that experience chronic insomnia. Thus, in the subsequent large trial, we will include some PCP suggestions about certain aspects of the training, such as to provide a more thorough discussion of the different components of therapy, to negotiate with patients the objectives of each session, and to instigate a more active follow-up of PCPs by use of periodic phone calls.

Recruitment and follow-up of participants and patients

We had difficulties in getting doctors and nurses to participate in this trial, and some of the participants did not include any patients. In our subsequent large study, it will be necessary to work with PCPs in the recruitment of patients and implementation of the intervention. Not all PCPs have the skills to learn the basics of CBT-i, so a more careful selection of doctors and nurses should be performed in the subsequent trial.

Additionally, we found that the recruitment of patients was difficult. We therefore plan to improve the recruitment process by use of poster invitations in health centers and in the community. Furthermore, as the PCPs proposed, we will adjust the eligibility for participation in subsequent large trial. To increase patient adherence to treatment, patients will be included if they present with more severe insomnia (ISI > 14) and have poorer sleep quality. The use of more stringent criteria could increase patient motivation to participate and these patients also have greater potential for improvement. Also, reminders to PCPs and patients will be used to increase the participation.

Results of the intervention

This study was not designed to test a hypothesis, and we therefore cannot place great significance on results, because no formal sample calculations were performed and there could be some imbalances in the pre-randomization covariates. Moreover, this was an external pilot study, and the patients recruited here will not be included in the subsequent large study [23].

Pilot and feasibility studies play an invaluable part of health research. We tried to be explicit as possible about the purpose of this pilot study, as proposed by Lancaster and by Arain $[36,38]$. Methodological rigor is achieved by using a well-conceived and well-designed study that has clear aims and objectives, and uses a high quality definitive randomized and controlled design.

Limitations

One of the main limitations is that we did not include assessments by participating patients. We originally wanted to assess the patients using interviews, but the study ended during the summer, and the residents left to work in hospitals or other health centers and could not perform this task. 
Fortunately, the participating PCPs reported feedback from some of their patients in the nominal groups, and we will consider these comments prior to the subsequent large trial.

This study had some characteristics of a feasibility study, in that we used the nominal group technique, to determine if a subsequent large trial would be feasible and reproducible. On the other hand, this study also had some characteristics of a pilot study, in that we focused on the processes to be

used in a large RCT, such as recruitment, randomization, treatment, and follow-up, to identify problems that might occur in the subsequent large study.

\section{Conclusions}

This external pilot-feasibility study indicated the need to address several key issues before performing the subsequent large clinical trial. We identified the need to adapt the intervention to the limited time available for PC visits. Additionally, the future intervention should mainly focus on behavioral therapy, because many PCPs consider cognitive therapy too complex for implementation in a PC setting. The PCPs also suggested the use of longer interventions and the receipt of more training. The additional training of PCPs is needed so they have sufficient skills to implement effective interventions. The reporting of these practical issues in this pilot study will help to prevent similar pitfalls and mistakes in the subsequent large trial.

\section{Abbreviations}

\section{CBT-i}

Cognitive behavioral therapy for chronic insomnia

IG

intervention group

CG

Control group

HADS

Hospital anxiety and depression scale

ISI

Insomnia Severity Index

MME

Mini Mental State Evaluation

PC

Primary Care

PCPs

primary care professionals

PSQI

Pittsburg Sleep Quality Index

UC

Usual care

UCG

Usual care group

\section{Declarations}

\section{Ethic approval and consent to participate}

All participants were informed about the study orally and with written information and provided written consent prior to being enrolled in the study. Ethical approval was granted by the Primary Care Research Committee of the Majorca Department of Primary Care, Balearic Health Service. Reference: PI14/019.

\section{Consent for publication}

Not applicable

\section{Availability of data and materials}

The datasets used and/or analyzed during the current study are available from the corresponding author on reasonable request.

\section{Competing interests}

The authors declare that they have no competing interests. 
Funding: This study was funded by annual grants of the Majorca Department of Primary Care (PI8/14). This funding source had no role in the design of the study, nor did it have any role in its execution, analyses, interpretation of the data, or decision to submit results.

\section{Author contributions:}

The study was conceived by IT, ME and ET with support from PLM, CR and MCVT. The intervention was designed by IT, ET, RP and MCVT. ET and IT designed the materials for patients and primary care professionals. ET and ME jointly coordinated the study development and data collection. Nominal groups were organized and analyzed by MCVT and ME. ME conducted the quantitative analysis and wrote the first draft of the manuscript with additional comments from IT and ET. All authors read the manuscript thoroughly and approved the final version.

Acknowledgements: The authors would like to acknowledge Carles Gil Ribes for assistance with reviewing the quality of databases and to Alfonso Leiva for his comments on the manuscript. The authors also thank Beatriz Yañez, Melany Puertas, Julio Olsen, Adriana Hemfelt, and Teresa Estrades for their contributions to the study.

\section{References}

1. Caballo VE, Salazar IC, Carrobles JA. Manual de Psicopatología y Trastornos Psicológicos. 2on edition. Madrid: Ediciones Pirámide; 2014.

2. Ohayon MM, Sagales T. Prevalence of insomnia in the general population of Spain. Sleep Med. 2010; doi: 10.1016/j.sleep.2010.02.018.

3. Torrens I, Argüelles-Vazquez R, Lorente-Montalvo P, Molero-Alfonso C, Esteva M. Prevalence of insomnia and characteristic of patients with insomnia in a health area of Majorca (Spain). Aten Primaria. 2019; doi: 10.1016/j.aprim.2018.02.014.

4. St-Onge MP, Grandner MA, Brown D, Conroy MB, Jean-Louis G, Coons M, Bhatt DL; American Heart Association Obesity, Behavior Change, Diabetes, and Nutrition Committees of the Council on Lifestyle and Cardiometabolic Health; Council on Cardiovascular Disease in the Young; Council on Clinical Cardiology; and Stroke Council. Circulation. 2016; doi: 10.1161/CIR.0000000000000444.

5. Lavie P. Sleep habits and sleep disturbances in industrial workers in Israel: main findings and some characteristics of workers complaining of excessive daytime sleepiness. Sleep. 1981; doi: 10.1093/sleep/4.2.147.

6. Léger D, Partinen M, Hirshkowitz M, Chokroverty S, Touchette E, Hedner J; EQUINOX. Daytime consequences of insomnia symptoms among outpatients in primary care practice: EQUINOX international survey. Sleep Med. 2010; doi: 10.1016/j.sleep.2010.04.018.

7. Sagberg F. Driver health and crash involvement: A case-control study. Accid Anal Prev. 2006; doi: 10.1016/j.aap.2005.06.018.

8. Daley M, Morin CM, LeBlanc M, Grégoire JP, Savard J. The economic burden of insomnia: direct and indirect costs for individuals with insomnia syndrome, insomnia symptoms, and good sleepers. Sleep. 2009; 32:55-64.

9. Wickwire EM, Shaya FT, Scharf SM. Health economics of insomnia treatments: The return on investment for a good night's sleep. Sleep Med Rev. 2016; doi: 10.1016/j.smrv.2015.11.004.

10. Glass J, Lanctôt KL, Herrmann N, Sproule BA, Busto UE. Sedative hypnotics in older people with insomnia: meta-analysis. BMJ. 2005; doi: 10.1136/bmj.38623.768588.47.

11. Holbrook AM, Crowther R, Lotter A, Cheng C, King D. Meta-analysis of benzodiazepine use in the treatment of insomnia. CMAJ. 2000; 162:225-233.

12. Morin CM. Insomnia: Psychological Assessment and management. New York: Guildford Press; 1993.

13. Mitchell MD, Gehrman P, Perlis M, Umscheid CA. Comparative effectiveness of cognitive behavioral therapy for insomnia: a systematic review. BMC Fam Pract. 2012; doi: 10.1186/1471-2296-13-40.

14. Smith MT, Perlis ML, Park A, Smith MS, Pennington J, Giles DE, et al. Comparative Meta-Analysis of Pharmacotherapy and Behavior Therapy for Persistent Insomnia. Am J Psychiatry. 2002; doi: 10.1176/appi.ajp.159.1.5.

15. Geiger-Brown JM, Rogers VE, Liu W, Ludeman EM, Downton KD, Diaz-Abad M. Cognitive behavioral therapy in persons with comorbid insomnia: A meta-analysis. Sleep Med Rev. 2015; doi: 10.1016/j.smrv.2014.11.007.

16. Espie CA, MacMahon KM, Kelly HL, Broofield NM, Douglas NJ, Engleman HM, et al. Randomized clinical effectiveness trial of nurse-administered small-group cognitive behavior therapy for persistent insomnia in general practice. Sleep. 2007; doi: 10.1093/sleep/30.5.574.

17. Morgenthaler T, Kramer M, Alessi C, Friedman L, Boehlecke B, Brown T et al. An American academy of sleep medicine report. Practice parameters for the psychological and behavioral treatment of insomnia: an update. Sleep. 2006; 29:1415-19.

18. Bluestein D, Healey AC, Rutledge CM. Acceptability of Behavioral Treatments for Insomnia. J Am Board Fam Med. 2011; doi: 10.3122/jabfm.2011.04.110108.

19. Griffiths F, Lindenmeyer A, Powell J, Lowe P, Thorogood M. Why Are Health Care Interventions Delivered Over the Internet? A Systematic Review of the Published Literature. J Med Internet Res. 2006; doi: 10.2196/jmir.8.2.e10.

20. Perils ML, Smith MT. How can we make and other BSM services widely available? J Clin Sleep Med. 2008; 4:11-3.

21. Aikens JE, Rouse ME. Help-Seeking for Insomnia among Adult Patients in Primary Care. J Am Fam Med. 2005; doi: 10.3122/jabfm.18.4.257.

22. Shayinde M, Pickering RM, Weatherall M. Questions asked and answered in pilot and feasibility randomized controlled trials. BMC Med Res Methodol. 2011; doi: 10.1186/1471-2288-11-117. 
23. Torrens I, Ortuño M, Guerra JA, Esteva M, Lorente P. Actitudes ante el insomnio de los médicos de AP de Mallorca. Atencion Primaria. 2016; doi: 10.1016/j.aprim.2015.06.012.

24. 25. Vidal-Thomàs MC, Yañez-Amorós B, Torrens I, Torres-Solera E, Esteva M. Conocimientos y actitudes de las enfermeras de Atención Primaria sobre el manejo del paciente con insomnio. Enferm Clin. 2017; doi: 1016/j.enfcli.2016.11.006 .

25. Buysse DJ. The Pittsburg Sleep Quality IndeX: A new instrument for psychiatric Practice and research. Psychiatry Res 1989; doi: 10.1016/01651781(89)90047-4.

26. Rico Fernández M. Propiedades clinimétricas de la versión castellana del cuestionario de Pittsburg. Vigilia-Sueño 1997; 9:81-4.

27. Quintana JM, Padierna A, Esteban C, Arostegui I, Bilbao A, Ruiz I: Evaluation of the psychometric characteristics of the Spanish version of the Hospital Anxiety and Depression Scale. Acta Psychiatr Scand 2003, doi: 10.1034/j.1600-0447.2003.00062.x.

28. Zigmond AS, Snaith RP: The hospital anxiety and depression scale. Acta Psychiatr Scand 1983, doi: 10.1111/j.1600-0447.1983.tb09716.x.

29. Bastien $\mathrm{CH}$, Vallières A, Morin CM. Validation of the Insomnia Severity Index as an outcome measure for insomnia research. Sleep Med. 2001; doi: 10.1016/s1389-9457(00)00065-4.

30. Sierra JC, Guillén-Serrano V, Santos-Iglesias P. [Insomnia Severity Index: some indicators about its reliability and validity on an older adult's sample]. Rev Neurol. 2008; 47:566-70.

31. Rai GS. The Mini-Mental State Examination. J Am Geriatr Soc. 1993; doi: 10.1111/j.1532-5415.1993.tb06721.x.

32. Lobo A, Saz P, Marcos G, Día JL, de la Cámara C, Ventura T, Morales Asín F, Fernando Pascual L, Montañés JA, Aznar S. Revalidation and standardization of the cognition mini-exam (first Spanish version of the Mini-Mental Status Examination) in the general geriatric population. Med Clin (Barc). 1999; 112:767-74.

33. 34. Delbecq AL, Van der Ven AH. A group process model for problem identification and programme planning. J Appl Behav Sci 1971; 7:466-92.

34. 35. Vicens C, Bejarano F, Sempere E, Mateu C, Fiol F, Socias I, Aragonès E, Palop V, Beltran JL, Piñol JL, Lera G, Folch S, Mengual M, Basora J, Esteva M, Llobera J, Roca M, Gili M, Leiva A. Comparative efficacy of two interventions to discontinue long-term benzodiazepine use: cluster randomised controlled trial in primary care. Br J Psychiatry. 2014; doi: 10.1192/bjp.bp.113.134650.

35. Lancaster GA, Dodd S, Willianson PR. Desing and analysis of pilot studies: recommendations for good practice. J Eval Clin Pract. 2004; doi: 10.1111/j..2002.384.doc.x..

36. Thabane L, Ma J, Chu R, Cheng J, Ismaila A, Rios LP, Robson R, et al. A tutorial on pilot studies: The what, why and how. BMC Medical Res Meth 2010, doi: 10.1186/1471-2288-10-1.

37. Arain M, Capbell MJ, Cooper CL, Lancaster GA. What is a pilot or feasibility study? A review of current practice and editorial policy. BMC Med Res Meth 2010; doi: 10.1186/1471-2288-10-67.

\section{Figures}




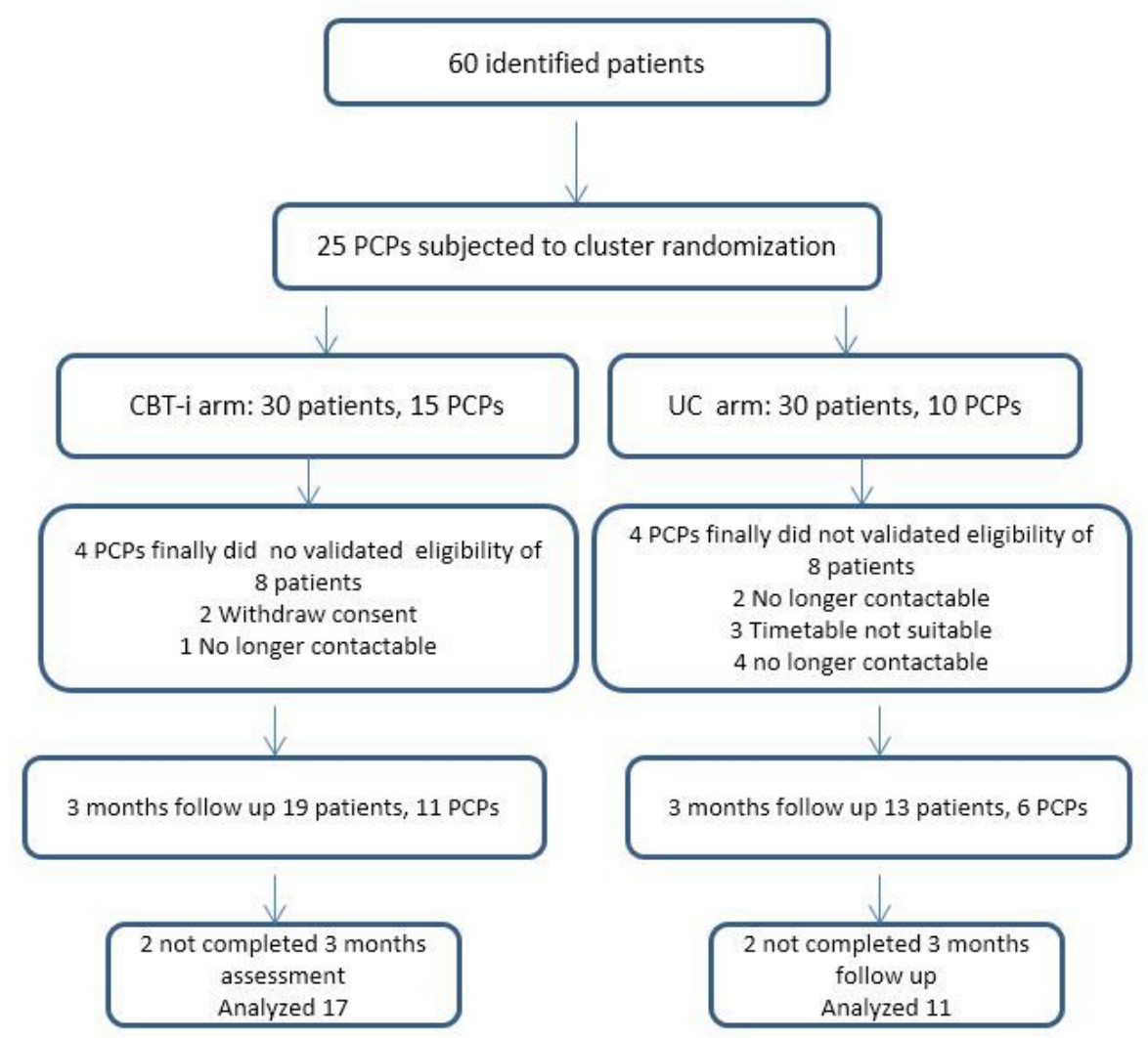

Figure 1

PCP participants and recruitment of patients (CONSORT flow diagram)

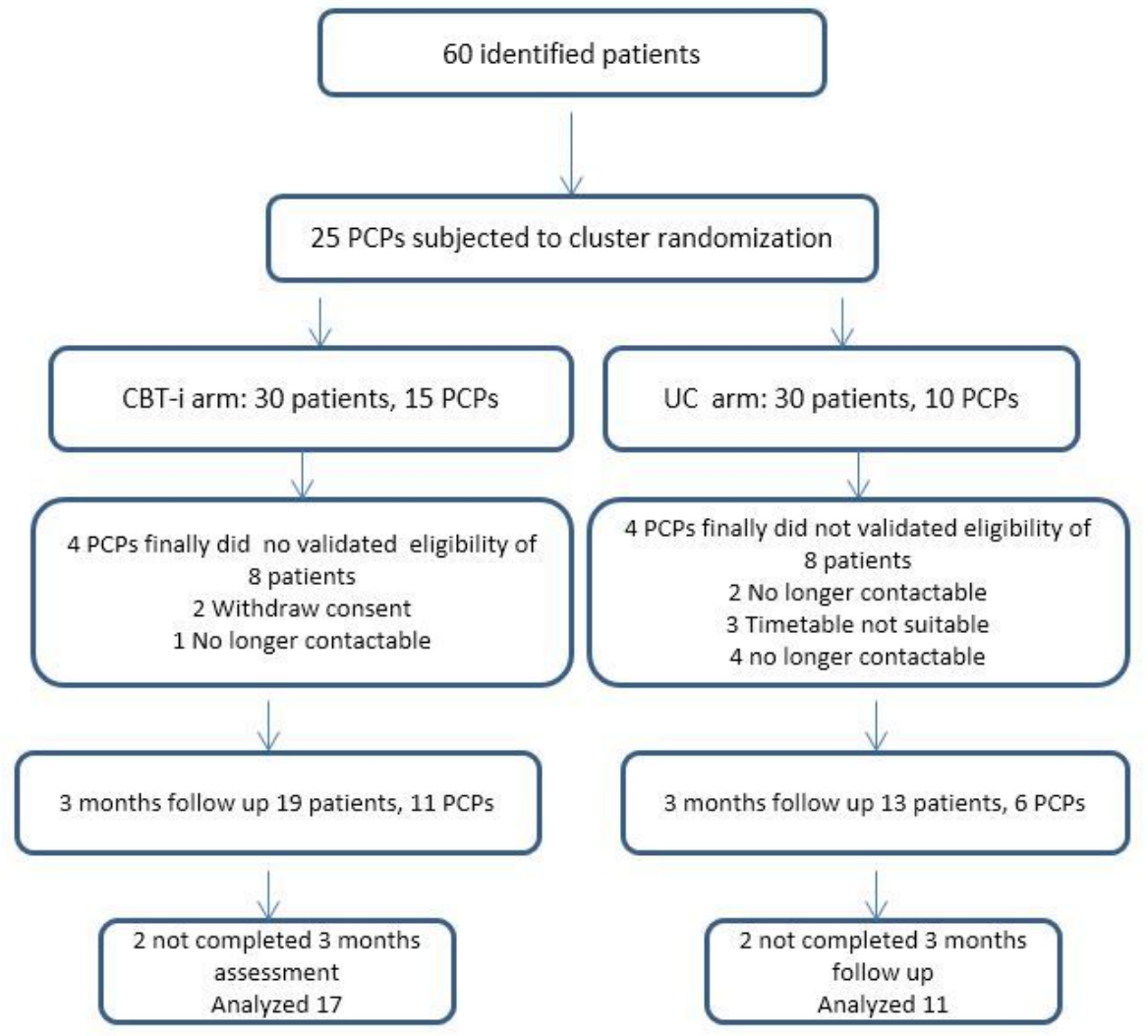

Figure 1

PCP participants and recruitment of patients (CONSORT flow diagram) 


\section{Supplementary Files}

This is a list of supplementary files associated with this preprint. Click to download.

- consortstatementtable.docx

- consortstatementtable.docx 